\title{
PENGARUH FRAUD PENTAGON TERHADAP FRAUDULENT FINANCIAL STATEMENT PADA PERUSAHAAN MANUFAKTUR DI BURSA EFEK INDONESIA
}

\section{Andrianus Andri}

Universitas Widya Dharma Pontianak, Indonesia

Email: andrianusandripaddlepop@gmail.com

\section{Abstrak}

Latar belakang: Laporan keuangan sebagai alat penyampaian informasi kepada pihak berkepentingan mengenai kondisi perusahaan, sering dalam pelaksanaanya terjadi salah saji yang dilakukan secara sengaja atau disebut fraudulent financial statement (AHMAD, 2022).

Tujuan penelitian: Tujuan penelitian ini untuk mengetahui pengaruh Financial Stability, External Pressure, Financial Target, Nature of Industry, External Auditor Quality, Auditor Change, Change of Directors, dan Frequent Number of CEO Photo terhadap fraudulent financial statement

Metode penelitian: Populasi dalam penelitian ini adalah 179 perusahaan sektor manufaktur di Bursa Efek Indonesia dan metode pengambilan sampel memakai purposive sampling dengan jumlah sampel didapat sebanyak 96 perusahaan. Bentuk penelitian yang digunakan adalah asosiatif. Teknik analisis menggunakan metode kuantitatif dengan analisis statistik deskriptif, uji asumsi klasik, dan uji multiple logistic regression menggunakan bantuan software SPSS versi 22.

Hasil penelitian: menunjukkan bahwa Financial Stability dan Financial Target berpengaruh positif terhadap Fraudulent Financial Statement. External Auditor Quality dan Change of Directors berpengaruh negatif terhadap Fraudulent Financial Statement, sedangkan External Pressure, Nature of Industry, Auditor Change, dan Frequent Number of CEO photo tidak berpengaruh terhadap Fraudulent Financial Statement.

Kesimpulan: Hasil penelitian menunjukkan bahwa Financial Stability dan Financial Target berpengaruh positif terhadap Fraudulent Financial Statement, External Auditor Quality dan Change of Directors berpengaruh negatif terhadap Fraudulent Financial Statement, sedangkan External Pressure, Nature of Industry, Auditor Change, dan Frequent Number of CEO photo tidak berpengaruh terhadap Fraudulent Financial Statement

Kata kunci: Fraud Pentagon, Fraudulent Financial Statement, M-Score, Laporan keuangan, dan Sektor Manufaktur

\section{Abstract}

Background Financial statements as a means of delivering information to interested parties regarding the condition of the company, often in its implementation there are intentional misstatements or called fraudulent financial statements (AHMAD, 2022).

The purpose of the study: The purpose of this study was to determine the effect of Financial Stability, External Pressure, Financial Target, Nature of Industry, External Auditor Quality, Auditor Change, Change of Directors, and Frequent Number of CEO Photo on fraudulent financial statements.

Research method: The population in this study were 179 companies in the manufacturing sector on the Indonesia Stock Exchange and the sampling method used purposive sampling with a total sample of 96 companies. The form of research used is associative. The analysis technique uses quantitative methods with descriptive statistical analysis, classical assumption tests, and multiple logistic regression tests using SPSS version 22 software

The results of the studyshows that Financial Stability and Financial Target have a positive effect on Fraudulent Financial Statements. External Auditor Quality and Change of Directors have a negative effect on Fraudulent Financial Statements, while External Pressure, Nature of Industry, Auditor Change, and Frequent Number of CEO photos have no effect on Fraudulent Financial Statements.

\begin{tabular}{ll}
\hline & $\begin{array}{l}\text { Andrianus Andri. (2021). Pengaruh Fraud Pentagon terhadap Fraudulent Financial Statement } \\
\text { pada Perusahaan Manufaktur di Bursa Efek Indonesia. Co-Value: Jurnal Ekonomi, Koperasi }\end{array}$ \\
How to cite: & Kewirausahaan Vol 12(1): 25-31 \\
\hline E-ISSN: & https://greenpublisher.id/ \\
\hline Published by: &
\end{tabular}


Conclusion: The results show that Financial Stability and Financial Target have a positive effect on Fraudulent Financial Statements, External Auditor Quality and Change of Directors have a negative effect on Fraudulent Financial Statements, while External Pressure, Nature of Industry, Auditor Change, and Frequent Number of CEO photos have no effect on Fraudulent Financial Statement

Keywords: Pentagon Fraud, Fraudulent Financial Statement, M-Score, Financial Statements, and Manufacturing Sector

Diterima: 25-12-2019 Direvisi: 5-01-2021 Disetujui: 6-01-2021

\section{PENDAHULUAN}

Laporan keuangan sebagai alat penyampaian informasi kepada pihak berkepentingan mengenai kondisi perusahaan, sering dalam pelaksanaanya terjadi salah saji yang dilakukan secara sengaja atau disebut fraudulent financial statement (AHMAD, 2022). Ada banyak faktor mengapa praktik fraudulent statement fraud sering terjadi seperti faktor sosial, industri, organisasi, karakteristik individual, dan psikologi yang memicu motivasi dan keinginan kuat untuk melakukan fraudulent financial statement (Softian, 2017). Praktik ini cukup sulit untuk dideteksi karena sifat fraud pada dasarnya tidak dapat diamati, diukur secara tepat, akurat, dan dalam jangka pendek karena berbagai motivasi dibalik tindakan fraud yang dilakukan hampir melibatkan upaya penyembunyian kejahatan (Syarifuddin et al., 2020).

Salah satu alat untuk mendeteksi tindakan kecurangan laporan keuangan yaitu pentagon fraud model yang terdiri dari 5 faktor mempengaruhi kecurangan laporan keuangan yaitu pressure, opportunity, rationalization, capability, dan arrogance (Faradiza, 2019). Berdasarkan uraian latar belakang yang dikemukakan, maka tujuan dari penelitian ini adalah untuk mengidentifikasi pengaruh financial stability, external pressure, financial target, nature of industry, external auditor quality, auditor change, change of directors, frequent number of CEO photo terhadap fraudulent financial statement (Pratama, 2019).

\section{METODE PENELITIAN}

Bentuk penelitian ini adalah penelitian asosiatif yang bersifat kuantitatif (Darna \& Herlina, 2018). Populasi dalam penelitian ini adalah 179 perusahaan sektor manufaktur di Bursa Efek Indonesia dan metode pengambilan sampel memakai purposive sampling dengan jumlah sampel didapat sebanyak 96 perusahaan dengan kriteria sampel yaitu perusahaan secara berturut-turut selama tahun 2015 hingga 2019 terdaftar di Bursa Efek Indonesia, laporan keuangan memakai mata uang Rupiah, dan data laporan keuangan yang dipakai lengkap. Data perusahaan diperoleh dari website resmi Bursa Efek Indonesia di www.idx.co.id (Susanti, 2014). Analisis data yang digunakan dalam penelitian ini adalah analisis multiple logistic regression dengan bantuan dari program SPSS versi 22 (Legowo, 2016).

\section{HASIL DAN PEMBAHASAN}

\section{Analisis Statistik Deskriptif}

TABEL 1 STATISTIK DESKRIPTIF

\begin{tabular}{lcrrrr}
\hline \multicolumn{7}{c}{ Descriptive Statistics } \\
\hline & N & Minimum & Maximum & Mean & Std. Deviation \\
\hline M-Score & 480 & 0 & 1 &, 29 &, 452 \\
\hline ACHANGE & 480 & $-5,8748$ &, 8985 &, 032549 &, 3609777 \\
\hline
\end{tabular}




\begin{tabular}{lrrrrr}
\hline LEV & 480 &, 0177 & 3,7445 &, 506048 &, 4107350 \\
\hline ROA & 480 &,- 4014 &, 7160 &, 049015 &, 1082516 \\
\hline REV & 480 & $-2,5963$ & 395,1650 & 1,627629 & 25,0899318 \\
\hline BIG4 & 480 & 0 & 1 &, 38 &, 485 \\
\hline AUDCHANGE & 480 & 0 & 1 &, 19 &, 396 \\
\hline COD & 480 & 0 & 1 &, 43 &, 495 \\
\hline CEOPic & 480 & 0 & 10 & 2,51 & 1,636 \\
\hline Vaid
\end{tabular}

Valid N (listwise) $\quad 480$

Sumber: data olahan SPSS 22, 2020

Berdasarkan pada Tabel 1 dapat diketahui total data yang dipakai dalam penelitian ini adalah 480 data dari 96 perusahaan sektor manufaktur di Bursa Efek Indonesia selama tahun 2015 hingga 2019. Valid N menunjukkan bahwa semua data telah terproses tanpa ada masalah.

1. Pengujian Asumsi Klasik.

a. Uji Autokorelasi.

Berdasarkan hasil pengujian autokorelasi dengan Run Test didapat nilai Asymp. Sig. (2-tailed) sebesar 0,455. Karena nilai Asymp. Sig. (2-tailed) >0,05 maka dapat disimpulkan model regresi tidak mengalami permasalahan autokorelasi.

b. Uji Multikolinearitas.

Hasil pengujian multikolinearitas menunjukkan nilai tolerance untuk delapan variabel independen memiliki nilai lebih dari 0,10 dan nilai VIF tidak ada yang lebih dari sepuluh sehingga dapat disimpulkan model regresi tidak mengalami permasalahan multikolinearitas.

2. Analisis Regresi Logistik.

a. Uji Kelayakan Model.

1) Overall Fit Model.

TABEL 2 PERBANDINGAN -2 LOG LIKELIHOOD BLOCK 0 DAN 1

$\begin{array}{lr}\text {-2Log Likelihood Block } 0 & 551,452 \\ \text {-2Log Likelihood Block } 1 & 515,070\end{array}$

Sumber: data olahan SPSS 22, 2020

Berdasarkan Tabel 2 nilai -2Log Likelihood block 0 dan 1 mengalami penurunan sebesar 49,941, menunjukkan bahwa dengan adanya penambahan variabel financial stability, external pressure, financial target, nature of industry, external auditor quality, auditor change, change of directors, dan frequent number of CEO photo dapat memperbaiki model atau dengan kata lain model fit dengan data.

Uji Hosmer dan Lemeshow's Goodness of Fit.

TABEL 3 UJI HOSMER AND LEMESHOW

\begin{tabular}{llllll}
\hline \multicolumn{9}{c}{ Hosmer and Lemeshow Test } \\
Step & Chi-square & df & Sig. & \\
1 & 4,259 & & 8 & &, 833 \\
\hline
\end{tabular}

Sumber: data olahan SPSS 22, 2020

Berdasarkan Tabel 3 hasil pengujian Hosmer-Lemeshow menunjukkan nilai signifikansi sebesar 0,833 karena nilainya lebih besar daripada 0,05 maka model dikatakan fit dan layak diterima.

b. Analisis Koefisien Determinasi. 
TABEL 4

UJI KOEFISIEN DETERMINASI

\begin{tabular}{cccc}
\hline \multicolumn{4}{c}{ Model Summary } \\
\hline \multirow{2}{*}{ Step } & -2 Log & Cox \& Snell R & Nagelkerke R \\
& likelihood & Square & Square \\
\hline 1 & $515,070^{\mathrm{a}}$ &, 076 &, 109 \\
\hline
\end{tabular}

a. Estimation terminated at iteration number 5 because parameter estimates changed by less than, 001 .

\section{Sumber: data olahan SPSS 22, 2020}

Berdasarkan Tabel 4 nilai Nagelkerke R Square sebesar 0,109 atau 10,9 persen artinya kemampuan variabel financial stability, external pressure, financial target, nature of industry, external auditor quality, change of auditor, change of directors, dan frequent number of CEO photo dalam menjelaskan variabilitas fraudulent financial statement sebesar 10,9 persen. Sedangkan sisanya yaitu 89,1 persen dijelaskan oleh variabel lain.

c. Matriks Klasifikasi.

TABEL 5

MATRIKS KLASIFIKASI

\begin{tabular}{|c|c|c|c|c|c|}
\hline \multicolumn{6}{|c|}{ Classification Table $^{\mathrm{a}}$} \\
\hline & \multirow{3}{*}{\multicolumn{2}{|c|}{ Observed }} & \multicolumn{3}{|c|}{ Predicted } \\
\hline & & & \multicolumn{2}{|c|}{ M-Score } & \multirow{2}{*}{ Percentage Correct } \\
\hline & & & Non Fraud & Fraud & \\
\hline \multirow[t]{3}{*}{$\overline{\text { Step } 1}$} & M-Score & Non Fraud & 320 & 8 & 97,6 \\
\hline & & Fraud & 118 & 14 & 10,6 \\
\hline & Overall $\mathrm{P}$ & centage & & & 72,6 \\
\hline
\end{tabular}

a. The cut value is , 500

Sumber: data olahan SPSS 22, 2020

Berdasarkan Tabel 5 prediksi perusahaan yang tidak terlibat praktik fraudulent financial statement adalah 97,6 persen. Sedangkan hasil prediksi perusahaan terlibat praktif fraudulent financial statement adalah 10,6 persen sehingga secara keseluruhan ketepatan klasifikasi adalah 72,6 persen.

d. Analisis Pengaruh.

TABEL 6

UJI MULTIPLE LOGISTIC REGRESSION

\begin{tabular}{|c|c|c|c|c|c|c|c|}
\hline \multicolumn{8}{|c|}{ Variables in the Equation } \\
\hline & & $\mathrm{B}$ & S.E. & Wald & $\mathrm{df}$ & Sig. & $\operatorname{Exp}(B)$ \\
\hline Step & ACHANGE & 3,077 & 819 & 14,127 & 1 & ,000 & 21,696 \\
\hline \multirow[t]{8}{*}{$1^{\mathrm{a}}$} & LEV & ,037 &, 500 &, 006 & 1 & ,940 & 1,038 \\
\hline & ROA & 2,523 & 1,228 & 4,223 & 1 &, 040 & 12,468 \\
\hline & REV & ,272 &, 823 &, 109 & 1 & ,741 & 1,312 \\
\hline & BIG4 &,- 651 & 269 & 5,866 & 1 &, 015 & ,521 \\
\hline & AUDCHANGE &, 184 & 272 & ,460 & 1 & 498 & 1,202 \\
\hline & COD &,- 522 & 232 & 5,072 & 1 & 024 & 593 \\
\hline & CEOPic &,- 027 & ,069 &, 154 & 1 & ,695 & ,973 \\
\hline & Constant &,- 801 & ,321 & 6,207 & 1 &, 013 & ,449 \\
\hline
\end{tabular}


a. Variable(s) entered on step 1: ACHANGE, LEV, ROA, REV, BIG4, AUDCHANGE, COD, CEOPic.

Sumber: data olahan SPSS 22, 2020

Berdasarkan Tabel 6 model persamaan regresi logistik dari estimasi parameter pada output SPSS variabel in the equation dalam penelitian ini adalah:

$\mathrm{Ln}(\mathrm{M}-$ Score $/ 1-\mathrm{M}$-Score $)=0,801+3,077 \mathrm{ACHANGE}+0,037 \mathrm{LEV}+2,523 \mathrm{ROA}+$ $0,272 \mathrm{REV}-0,651 \mathrm{BIG} 4+0,184 \mathrm{AUDCHANGE}-$ 0,522COD - 0,027CEOPIC

Financial stability berpengaruh positif terhadap fraudulent financial statement (Lestari \& Henny, 2019). Financial stability memiliki nilai signifikansi sebesar 0,000. Hal ini berarti financial stability berpengaruh positif terhadap fraudulent financial statement. External pressure berpengaruh positif terhadap fraudulent financial statement (Tiffani \& Marfuah, 2015). External pressure memiliki nilai signifikansi sebesar 0,940. Hal ini berarti external pressure tidak berpengaruh terhadap fraudulent financial statement (Yulia, 2018). Financial target berpengaruh positif terhadap fraudulent financial statement. Financial target memiliki nilai signifikansi 0,040 . Hal ini berarti financial target berpengaruh positif terhadap fraudulent financial statement.

Nature of industry berpengaruh positif terhadap fraudulent financial statement (Yesiariani \& Rahayu, 2017). Nature of industry memiliki nilai signifikansi sebesar 0,741 . Hal ini berarti nature of industry tidak berpengaruh terhadap fraudulent financial statement. External auditor quality berpengaruh negatif terhadap fraudulent financial statement (Hanifa \& Laksito, 2015). External auditor quality memiliki nilai signifikansi 0,015 (Sihombing \& Laksito, 2017). Hal ini berarti external auditor quality berpengaruh negatif terhadap fraudulent financial statement. Auditor change berpengaruh positif terhadap fraudulent financial statement (Lestari \& Henny, 2019). Auditor change memiliki nilai signifikansi sebesar 0,498. Hal ini berarti auditor change tidak berpengaruh terhadap fraudulent financial statement.

Change of directors berpengaruh negatif terhadap fraudulent financial statement Change of directors memiliki nilai signifikansi 0,024 (Agusputri \& Sofie, 2019). Hal ini berarti change of directors berpengaruh negatif terhadap fraudulent financial statement. Frequent number of $C E O$ photo berpengaruh positif terhadap fraudulent financial statement. Frequent number of CEO photo memiliki nilai signifikansi sebesar 0,695. Hal ini berarti frequent number of $C E O$ photo tidak berpengaruh terhadap fraudulent financial statement.

\section{KESIMPULAN}

Hasil penelitian menunjukkan bahwa Financial Stability dan Financial Target berpengaruh positif terhadap Fraudulent Financial Statement, External Auditor Quality dan Change of Directors berpengaruh negatif terhadap Fraudulent Financial Statement, sedangkan External Pressure, Nature of Industry, Auditor Change, dan Frequent Number of CEO photo tidak berpengaruh terhadap Fraudulent Financial Statement. Hasil analisis menunjukkan nilai koefisien determinasi hanya 10,9 persen, sedangkan sisanya 89,1 persen dipengaruhi oleh faktor lain maka penulis menyarankan mempertimbangkan penelitian selanjutnya untuk memakai variabel lain dalam menguji pengaruh terhadap Fraudulent Financial Statement misalnya variabel personal financial needs, ineffective monitoring, total accrual, dan organizational structure. 


\section{BIBLIOGRAFI}

Agusputri, H., \& Sofie, S. (2019). Faktor-Faktor Yang Berpengaruh Terhadap Fraudulent Financial Reporting Dengan Menggunakan Analisis Fraud Pentagon. Jurnal Informasi, Perpajakan, Akuntansi, Dan Keuangan Publik, 14(2), 105-124.

AHMAD, H. F. (2022). PENDETEKSIAN KECURANGAN LAPORAN KEUANGAN DENGAN MENGGUNAKAN BENEISH RATIO INDEXPADA PERUSAHAAN MANUFAKTUR YANG LISTING DI BURSA EFEK INDONESIA (BEI) TAHUN 2017-2019. UNIVERSITAS ISLAM NEGERI RADEN INTAN LAMPUNG.

Darna, N., \& Herlina, E. (2018). Memilih Metode Penelitian Yang Tepat: Bagi Penelitian Bidang Ilmu Manajemen. Jurnal Ekonologi Ilmu Manajemen, 5(1), 287-292.

Faradiza, S. A. (2019). Fraud pentagon dan kecurangan laporan keuangan. EkBis: Jurnal Ekonomi Dan Bisnis, 2(1), 1-22.

Hanifa, S. I., \& Laksito, H. (2015). Pengaruh Fraud Indicators Terhadap Fraudulent Financial Statement: Studi Empiris Pada Perusahaan Yang Listed di Bursa Efek Indonesia (BEI) Tahun 2008-2013. Diponegoro Journal of Accounting, 4(4), 411425.

Legowo, M. B. (2016). Perbandingan Antara Metode Discriminant Analysis Dan Logistic Regression Untuk Analisa Faktor-faktor Yang Mempengaruhi Prestasi Akademik Mahasiswa. Jurnal Teknik Informatika Dan Sistem Informasi, 2(3).

Lestari, M. I., \& Henny, D. (2019). Pengaruh Fraud Pentagon Terhadap Fraudulent Financial Statements Pada Perusahaan Perbankan Yang Terdaftar Di Bursa Efek Indonesia Tahun 2015-2017. Jurnal Akuntansi Trisakti, 6(1), 141-156.

Pratama, M. W. (2019). IDENTIFIKASI KECURANGAN LAPORAN KEUANGAN DENGAN MENGGUNAKAN ANALISIS FRAUD PENTAGON (Perusahaan Manufaktur yang Terdaftar di Bursa Efek Indonesia pada Tahun 2015-2017). Universitas Islam Indonesia.

Sihombing, M. A. R., \& Laksito, H. (2017). Pengaruh karakteristik komite audit dan kualitas auditor eksternal terhadap manajemen laba. Diponegoro Journal of Accounting, 6(4), 285-294.

Softian, P. A. (2017). Pengaruh Kesesuaian Kompensasi, Motivasi Dan Budaya Etis Organisasi Terhadap Kecurangan Laporan Keuangan daerah (studi empiris pada SKPD Kab Lima puluh kota). Jurnal Akuntansi, 5(1).

Susanti, F. (2014). Pengaruh Likuiditas, Kebijakan Deviden, Struktur Aset, Ukuran Perusahaan dan Pertumbuhan Penjualan terhadap Kebijakan Hutang pada Perusahaan Manufaktur yang Terdaftar di Bursa Efek Indonesia Tahun 2010-2013. Jurnal Akuntansi.

Syarifuddin, S., Sayuti, M. N., \& Hakim, S. (2020). Analisis Fraud Syariah Dalam Mengukur Efektivitas Program Kredit Pemilikan Rumah (KPR) Bersubsidi di Perumahan Kecipir.

Tiffani, L., \& Marfuah, M. (2015). Deteksi financial statement fraud dengan analisis fraud triangle pada perusahaan manufaktur yang terdaftar di bursa efek Indonesia. Jurnal Akuntansi Dan Auditing Indonesia, 19(2), 112-125.

Yesiariani, M., \& Rahayu, I. (2017). Deteksi financial statement fraud: Pengujian dengan fraud diamond. Jurnal Akuntansi Dan Auditing Indonesia, 21(1), 49. 
Yulia, Y. (2018). PENGARUH ELEMEN FRAUD DIAMOND THEORY DALAM MENDETEKSI FINANCIAL STATEMENT FRAUD (Studi Empiris pada

Perusahaan Manufaktur yang Terdaftar di Bursa Efek Indonesia Tahun 2012-2016).

Jurnal Akuntansi, 6(3).

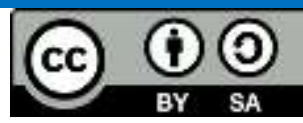

This work is licensed under a Creative Commons Attribution-ShareAlike 4.0 International License 